\title{
A phase I pharmacokinetic study of hypoxic abdominal stop-flow perfusion with gemcitabine in patients with advanced pancreatic cancer and refractory malignant ascites
}

\author{
Andrea Kuemmerle $\cdot$ Laurent A. Decosterd · Thierry Buclin · Danielle Liénard • \\ Roger Stupp · Pierre-Guy Chassot · François Mosimann • Ferdy Lejeune
}

Received: 18 December 2007 / Accepted: 17 March 2008 / Published online: 28 June 2008

(C) Springer-Verlag 2008

\begin{abstract}
Purpose As no curative treatment for advanced pancreatic and biliary cancer with malignant ascites exists, new modalities possibly improving the response to available chemotherapies must be explored. This phase I study assesses the feasibility, tolerability and pharmacokinetics of a regional treatment of gemcitabine administered in escalating doses by the stop-flow approach to patients with advanced abdominal malignancies (adenocarcinoma of the pancreas, $n=8$, and cholangiocarcinoma of the liver, $n=1)$.

Experimental design Gemcitabine at 500, 750 and $1,125 \mathrm{mg} / \mathrm{m}^{2}$ was administered to three patients at each dose level by loco-regional chemotherapy, using hypoxic abdominal stop-flow perfusion. This was achieved by an aorto-caval occlusion by balloon catheters connected to an extracorporeal circuit. Gemcitabine and its main metabolite
\end{abstract}

$2^{\prime}, 2^{\prime}$-difluorodeoxyuridine (dFdU) concentrations were measured by high performance liquid chromatography with UV detection in the extracorporeal circuit during the 20 min of stop-flow perfusion, and in peripheral plasma for $420 \mathrm{~min}$. Blood gases were monitored during the stop-flow perfusion and hypoxia was considered stringent if two of the following endpoints were met: $\mathrm{pH} \leq 7.2, \mathrm{pO}_{2}$ nadir ratio $\leq 0.70$ or $p \mathrm{CO}_{2}$ peak ratio $\geq 1.35$. The tolerability of this procedure was also assessed.

Results Stringent hypoxia was achieved in four patients. Very high levels of gemcitabine were rapidly reached in the extracorporeal circuit during the $20 \mathrm{~min}$ of stop-flow perfusion, with $C_{\max }$ levels in the abdominal circuit of 246 $( \pm 37 \%), 2,039( \pm 77 \%)$ and $4,780( \pm 7.3 \%) \mu \mathrm{g} / \mathrm{ml}$ for the three dose levels 500,750 and $1,125 \mathrm{mg} / \mathrm{m}^{2}$, respectively. These $C_{\max }$ were between $13( \pm 51 \%)$ and $290( \pm 12 \%)$ times higher than those measured in the peripheral plasma.
A. Kuemmerle · L. A. Decosterd · T. Buclin Division de Pharmacologie Clinique,

Département de Médecine, Centre Hospitalier

Universitaire Vaudois, Lausanne, Switzerland

D. Liénard · R. Stupp · F. Lejeune

Centre Pluridisciplinaire d'Oncologie,

Centre Hospitalier Universitaire Vaudois,

Lausanne, Switzerland

F. Mosimann

Service de Chirurgie Viscérale,

Centre Hospitalier Universitaire Vaudois,

Lausanne, Switzerland

P.-G. Chassot

Service d'Anesthésiologie,

Centre Hospitalier Universitaire Vaudois,

Lausanne, Switzerland
Present Address:

D. Liénard · F. Lejeune

Service d'Oncologie Médicale, Hôpital Erasme,

Université Libre de Bruxelles, Brussels, Belgium

F. Mosimann

Service de Chirurgie, Département de Chirurgie,

Faculté de Médecine et des Sciences de la Santé,

Université de Sherbrooke, 3001-12e Avenue Nord.,

Sherbrooke, QC, J1H 5N4 Canada

L. A. Decosterd $(\bowtie)$

Laboratory of Clinical Pharmacology and Toxicology,

Centre Hospitalier Universitaire Vaudois and University

of Lausanne, BH18-218, 1011 Lausanne, Switzerland

e-mail: laurentarthur.decosterd@chuv.ch 
Similarly, the abdominal exposure to gemcitabine, calculated as $\mathrm{AUC}_{\mathrm{t} 0-20}$, was between $5.5( \pm 43 \%)$ and 200 $( \pm 66 \%$ )-fold higher than the systemic exposure. Locoregional exposure to gemcitabine was statistically higher in presence of stringent hypoxia $\left(P<0.01\right.$ for $C_{\max }$ and $\mathrm{AUC}_{\mathrm{t} 0-20}$, both normalised to the gemcitabine dose). Toxicities were acceptable considering the complexity of the procedure and were mostly hepatic; it was not possible to differentiate the respective contributions of systemic and regional exposures. A significant correlation $(P<0.05)$ was found between systemic $C_{\max }$ of gemcitabine and the nadir of both leucocytes and neutrophils.

Conclusions Regional exposure to gemcitabine-the current standard drug for advanced adenocarcinoma of the pancreas-can be markedly enhanced using an optimised hypoxic stop-flow perfusion technique, with acceptable toxicities up to a dose of $1,125 \mathrm{mg} / \mathrm{m}^{2}$. However, the activity of gemcitabine under hypoxic conditions is not as firmly established as that of other drugs such as mitomycin C, melphalan or tirapazamine. Further studies of this investigational modality, but with bioreductive drugs, are therefore warranted first to evaluate the tolerance in a phase I study and later on to assess whether it does improve the response to chemotherapy.

Keywords Gemcitabine - Hypoxic stop-flow perfusion Pancreas cancer

\section{Introduction}

Cancer of the exocrine pancreas represents a major health burden in developed countries. In the United States, it was reported in 2000 as the fourth leading cause of cancerrelated death for both men and women, while in Europe it ranked sixth [1]. Because of difficulties in diagnosis, the aggressiveness of tumour growth and the lack of effective systemic therapies, the one and five year survival rates remain below 25 and $5 \%$, respectively $[1,2]$.

Considering the very poor prognosis of advanced pancreatic cancer with malignant ascites, and the absence of efficient new drugs, innovative modalities that may possibly improve, even modestly, the clinical response to available chemotherapies deserve exploration. A phase I study was therefore initiated, aiming at assessing the feasibility, tolerability and pharmacokinetics of a regional chemotherapeutic treatment of gemcitabine administered by the stopflow technique. The stop-flow concept was introduced in 1993 by Aigner as a semi-invasive loco-regional drug delivery approach [3]: the pharmacokinetic exposure to intra-arterial chemotherapy can be markedly enhanced when the arterial blood flow is reduced immediately after drug injection. To that purpose, Aigner et al. suggested to inflate a balloon catheter in the main afferent artery to slow down drug wash-out (arterial inflow occlusion). Pancreatic, gastric and pelvic tumours as well as peritoneal carcinomatosis are the main potential indications for this approach. However, the increase in drug exposure remains limited by the unavoidable drug wash out from the target organ into the venous stream. Thus, in order to further increase drug exposure during stop-flow, it may be possible, to add a venous outflow occlusion to establish a recirculation perfusion circuit (Fig. 1). This stop-flow perfusion technique is well suited for large body segments such as the thoracic and abdominal cavities in the pelvis and the limb [3-5].

There is currently controversy regarding the efficacy of such treatments: the first stop-flow trials (1993-1996) were promising with overall tumour responses up to $57 \%[4,6]$, but later trials (1998-present) were unable to confirm these results [7-10]. However, the distribution and concentrations of the antineoplastic drugs in the regional and systemic compartments of the circuit have not been thoroughly studied. To the best of our knowledge, only one clinical pharmacokinetic trial has been published in this setting [10]. Given this limited information, there is a need to define more precisely the local and systemic disposition of anticancer drugs administered through this manner before phase II or III trials are undertaken.

Gemcitabine chemotherapy is presently the standard of care for advanced pancreatic adenocarcinoma and has a favourable safety profile when administered systemically. This is why this drug was selected for this "proof-of-con-

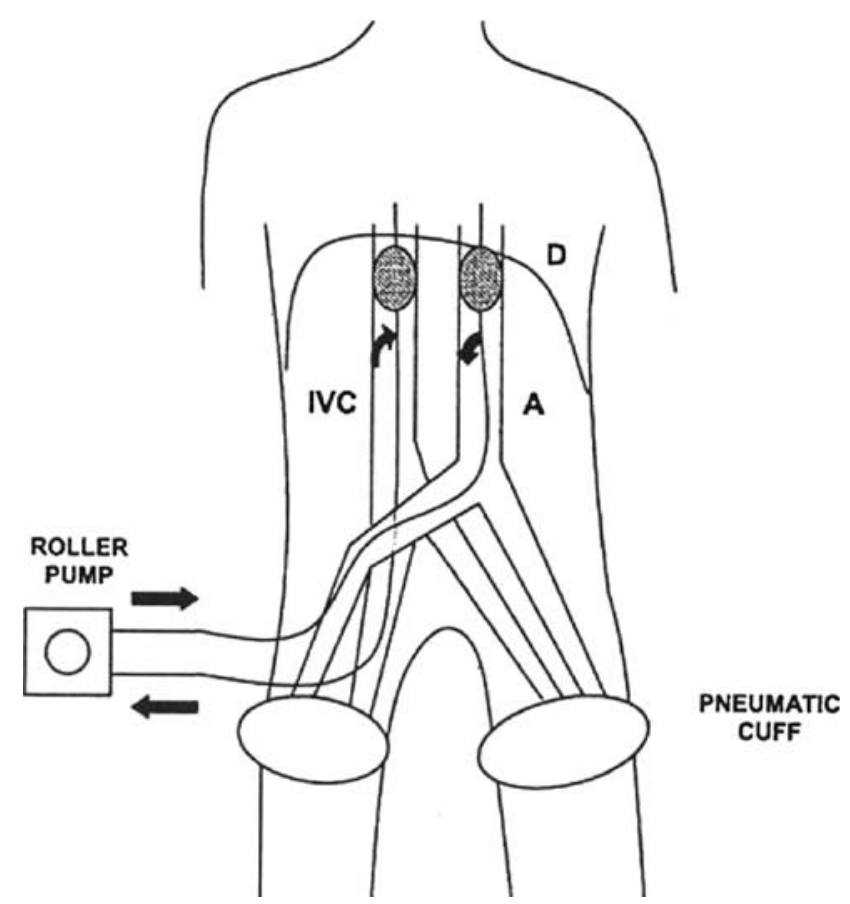

Fig. 1 Abdominal stop-flow perfusion (from Pilati et al. [5]). IVC, inferior vena cava; $A$, aorta; $D$, diaphragm 
cept" study, even though its therapeutic efficacy under hypoxic conditions is not known.

This phase I study assesses the feasibility and tolerability of a regional treatment of gemcitabine administered by hypoxic abdominal stop-flow perfusion to patients with advanced pancreatic cancer or refractory malignant ascites. It also describes the regional and systemic pharmacokinetic profiles of gemcitabine and its main metabolite $2^{\prime}, 2^{\prime}$-difluorodeoxyuridine $(\mathrm{dFdU})$.

\section{Methods}

\section{Patients}

This phase I study was approved by the local Ethics Committee of our Institution. At inclusion, all patients suffered from a histologically proven stage II, III or IV carcinoma of the pancreas that had been treated according to current state of the art (resection or bypass surgery, interventional endoscopy or radiology, palliative radiotherapy, systemic chemotherapy). Stage II patients were included in case of residual disease or failure of radical resection; stage III patients were included in all cases, and stage IV patients exclusively if intra-abdominal metastases were the only site of dissemination. Patients suffering from malignant ascites due to intra-abdominal carcinomas, resistant to conventional treatments could also be included. Patients had to be older than 18 years of age, have a performance score of less than or equal to 2 on the Eastern Cooperative Oncology Group (ECOG) scale, and have intact liver and renal function tests. All gave informed written consent and knew that the protocol did not aim at cure. None had significant cardiac failure (New-York Medical Heart Association, classes III and IV), severe disease of the central nervous system (tumours, psychiatric disorders, stroke), peripheral arterial disease (grade II or more according to Fontaine), an organ allograft, haemorrhagic diathesis, active infectious disease, an active peptic ulcer, a history of deep vein thrombosis or a previous radiotherapy treatment involving more than $20 \%$ of haematopoietic bone marrow.

\section{Study design}

The primary study endpoint was the assessment of the pharmacokinetic profile and tolerability of gemcitabine administered by stop-flow perfusion. The evaluation of gemcitabine anti-tumoral effect was a secondary endpoint. All patients were scheduled to receive subsequent systemic gemcitabine treatments $\left(1,000 \mathrm{mg} / \mathrm{m}^{2}\right.$ every week for 3 weeks, followed by 1 week off) after closure of the study.
Three dose levels of gemcitabine were tested in ascending order in three sets of patients. The initial dose level was chosen at $500 \mathrm{mg} / \mathrm{m}^{2}$ (i.e. $50 \%$ of a usual weekly dose by intravenous infusion), and subsequent escalations were by $50 \%$ steps (i.e. 750 and $1,125 \mathrm{mg} / \mathrm{m}^{2}$ ). In case of a dose-limiting toxicity (DLT), an additional three patients had to be treated at the same dose level. Treatment at an escalated dose was only given if less than three of six patients had experienced a toxic adverse event. DLT was defined as a lasting grade III or any grade IV toxicity according to the common terminology criteria for adverse events (CTCAE) [11].

\section{Stop-flow procedure}

The stop-flow procedure was performed under general anesthaesia by introducing an arterial balloon catheter into the aorta via the common femoral artery up to the diaphragm and a venous balloon catheter via the sapheno-femoral junction up to the right atrium under radioscopic and radio-angiographic control (Fig. 1). Systemic anticoagulation was achieved with heparin $(150 \mathrm{U} / \mathrm{kg})$. An extracorporeal circuit (without a blood oxygenator) was then connected, draining the blood from the vena cava and reinfusing it into the aorta. This circuit was primed with $200 \mathrm{ml}$ of Hartmann solution and 5,000 $\mathrm{U}$ heparin and started at a flow rate of $100 \mathrm{ml} / \mathrm{min}$. After checking of the balloons' position, the circulation in the lower limbs was interrupted by pneumatic cuffs at the root of the thighs and aorto-caval flow block was achieved by inflating the balloon catheters. The flow of the circuit was set between 100 and $300 \mathrm{ml} / \mathrm{min}$ according to blood outflow capacity. A gemcitabine bolus was then injected into the circuit and allowed to circulate in the abdomen until the end of a 20 min stop-flow period.

At the end, blood circulation was re-established by deflating first the caval catheter balloon, then the aortic one and finally by removing the limb cuffs. The balloon catheters were removed and the vessels sutured.

The level of hypoxia reached during the stop-flow procedure was considered stringent if at least two of the following three criteria were met: $\mathrm{pH} \leq 7.2, p \mathrm{O}_{2}$ nadir ratio $\leq 0.70 \mathrm{mmHg}$ and $p \mathrm{CO}_{2}$ peak ratio $\geq 1.35 \mathrm{mmHg}$.

\section{Optimization of caval balloon positioning}

In spite of an apparently complete venous block at the vena cava's level, as assessed by angiography, transoesophageal ultrasonography revealed residual blood flow in some patients, which could have caused significant drug leakage into the systemic circulation. In this situation, ultrasonography enabled the surgeon to optimalise the vena cava' balloon position at the level of right atrium. 


\section{Clinical follow-up and evaluation}

The patients were monitored closely during the month following the stop-flow procedure and had weekly medical visits. Tolerance of the stop-flow perfusion with gemcitabine was evaluated for 3 weeks: haematologic parameters were checked three times a week, while renal and hepatic functions were controlled three times during the first week and then weekly. The common terminology criteria for adverse events (CTCAE) was used to grade organ damage [11].

In patients with pancreas carcinoma, the anti-tumoral effect was assessed by CT-scan 2 months after treatment and then every 3 months. The markers carbohydrate antigen 19-9 (CA 19-9) and carcinoembryonic antigen (CEA) were checked every month. In case of malignant ascites, the umbilical perimeter was measured and CT-scan evaluation, in case of a tumoral mass, was done as above. Depending on the tumour histology, other markers were also followed.

\section{Pharmacokinetics}

\section{Samples}

Blood samples were collected into heparinised tubes (Monovettes $^{\circledR} 5.5 \mathrm{ml}$, Sarstedt, Nümbrecht, Germany) added with $50 \mu \mathrm{l}$ of the cytidine deaminase inhibitor tetrahydrouridine (THU; $1 \mathrm{mg} / \mathrm{ml}$ solution) from Calbiochem (supplied by Juro, Luzern, Switzerland). Arterial blood samples were collected from the extracorporeal circuit before and then at 2, 4, 6, 8, 10, 15 and 20 min after gemcitabine injection in the perfusion circuit. Peripheral venous blood samples were collected before and at 2, 4, 6, 8, 10, $15,20,25,30,35,40,50,60,90 \mathrm{~min}$, and then $2,3,4,6 \mathrm{~h}$ after gemcitabine injection. Plasma was separated by centrifugation at $1,500 \mathrm{~g}$ for $10 \mathrm{~min}$. All samples were stored at $-20^{\circ} \mathrm{C}$ until analysis.

\section{Analytical method}

The plasma concentrations of gemcitabine and its inactive metabolite dFdU were determined by a normal-phase HPLC method with UV detection. Gemcitabine HCl (LY2643689) and dFdU (LY198791) were generously supplied by Eli Lilly (Indianapolis, USA). The related compound lamivudine $\left(3 \mathrm{TC}^{\circledR}\right)$ was purchased from GlaxoSmithKline (Münchenbuchsee, Switzerland) to be used as internal standard. Briefly, a $1 \mathrm{ml}$-sample aliquot was spiked with $100 \mu \mathrm{l}$ of internal standard aqueous solution $(12.5 \mu \mathrm{g} / \mathrm{ml})$ prior to the protein precipitation step. Then, $500 \mu$ l acetone (E. Merck, Darmstadt, Germany) and $50 \mu \mathrm{l}$ zinc sulphate (E. Merck, Darmstadt, Germany) $70 \%$ aqueous solution were added. The samples were mixed and centrifuged at 22,000 $\mathrm{g}$ for
$10 \mathrm{~min}$ at $+4^{\circ} \mathrm{C}$. The supernatant was evaporated to dryness at $60^{\circ} \mathrm{C}$ for 75 min under nitrogen stream and the solid residue was resuspended in $150 \mu \mathrm{l}$ methanol (E. Merck, Darmstadt, Germany) and sonicated for $15 \mathrm{~min}$. The nonsolubilised solid residue was eliminated by centrifugation at $22,000 \mathrm{~g}$ for $20 \mathrm{~min}$ at $4^{\circ} \mathrm{C}$. The particle-free samples were introduced into HPLC $0.5 \mathrm{ml}$ amber glass vials (i.e. protected from light) (Laubscher Labs, Miecourt, Switzerland). A volume of $10 \mu \mathrm{l}$ was subjected to HPLC analysis onto a YMC-pack polyamine II column, $250 \mathrm{~mm} \times 4.6 \mathrm{~mm}$ i.d., S-5 $\mu \mathrm{m}, 12 \mathrm{~nm}$ (YMC, Schermbeck, Germany) equipped with a YMC-pack polyamine II guard column, $10 \mathrm{~mm} \times 4 \mathrm{~mm}$ i.d. filled with the same packing material (YMC, Schermbeck, Germany). The mobile phase was delivered using a gradient elution of acetonitrile (E. Merck, Darmstadt, Germany) and an aqueous solution containing $30 \mathrm{mM}$ of ammonium formate (Fluka, Buchs, Switzerland) adjusted to pH 5.5 with formic acid 1\%: $95 / 5$ at $0 \mathrm{~min} \rightarrow 85 / 15$ at $22 \mathrm{~min}, \rightarrow 0 / 100$ at $27 \mathrm{~min}, \rightarrow 0 / 100$ at $42 \mathrm{~min}, \rightarrow 95 / 5$ at $57 \mathrm{~min}, \rightarrow 95 / 5$ at $65 \mathrm{~min}$ delivered at $1 \mathrm{ml} / \mathrm{min}(0.8 \mathrm{ml} / \mathrm{min}$ between 27 and $42 \mathrm{~min}$, washing time). The analytes were detected using a spectrophotometric UV-DAD detector set at $272 \mathrm{~nm}$. The retention times for $\mathrm{dFdU}$, lamivudine and gemcitabine are 11.2, 13.4 and $18.5 \mathrm{~min}$ respectively. Calibration curves were obtained by quadratic weighted $1 /$ concentration $^{2}\left(1 / x^{2}\right)$ least-squares linear regression analysis of the peak ratio of gemcitabine and $\mathrm{dFdU}$ to internal standard, versus the corresponding concentration ratio in each standard solution. The calibration curves were linear over the range of $0.050-10 \mu \mathrm{g} / \mathrm{ml}$ for gemcitabine and $0.075-10 \mu \mathrm{g} / \mathrm{ml}$ for $\mathrm{dFdU}$. The method was validated according to the FDA and SFSTP (Société Française des Sciences et Techniques Pharmaceutiques) recommendations $[12,13]$ as well as the guidelines of the Washington Conference [14, 15]. The method was found to be precise with coefficients of variation (CV\%) within 3.6$6.8 \%$, and accurate with $95 \%$ confidence limits comprised between 6.9 and $13.4 \%$ for gemcitabine and $\mathrm{dFdU}$ at the three quality control samples' concentration level. The limit of detection was experimentally determined to $0.0125 \mu \mathrm{g} /$ $\mathrm{ml}$ for gemcitabine and $0.01875 \mu \mathrm{g} / \mathrm{ml}$ for $\mathrm{dFdU}$.

\section{Pharmacokinetic data analysis}

The maximum plasma concentration $\left(C_{\max }\right)$ and the time to maximum $\left(t_{\max }\right)$ were determined by direct data examination for gemcitabine and $\mathrm{dFdU}$ in the extracorporeal system and in the peripheral plasma. The terminal half-life $\left(t_{1 / 2 \text { term }}\right)$ was calculated in the peripheral plasma as $\log (2) / \lambda_{z}$, where $\lambda_{z}$ represents the terminal elimination rate constant, i.e. the absolute value of the slope of the terminal log-linear phase. Gemcitabine and dFdU exposures in the extracorporeal system and in the peripheral plasma during the 20 min of 
stop-flow were expressed as the corresponding area under the concentration-time curve $\left(\mathrm{AUC}_{0-20}\right)$ calculated by the linear trapezoidal rule. The total systemic drug exposure was expressed as the area under the concentration-time curve $\left(\mathrm{AUC}_{0-\infty}\right)$ extrapolated to infinity, deduced from the terminal elimination rate constant $\lambda_{z}$. Regional versus systemic drug exposure ratios were obtained by dividing the regional $C_{\max }$ and $\mathrm{AUC}_{t 0-20}$ values by the corresponding systemic values for each patient.

All the data were calculated separately for each patient. The results are presented as geometric mean and relative coefficient of variation $(\mathrm{CV}, \%)$ at each drug dose level. A Student's $T$ test was used to assess differences amongst the PK parameters between patients with and without stringent hypoxia during perfusion. Statistical significance was assumed at $P<0.05$.

\section{Results}

\section{Patients' characteristics}

From September 1997 to October 2002, nine patients were included in the study. Patients' demographics are described in Table 1 . The male/female ratio was $6 / 3$. The median age was 56 years (range 45-71). All patients had a performance status $\leq 2$. Eight patients had adenocarcinoma of the pancreas (patients 1-8) including three (patients 1, 5 and 6) with liver metastases at the time of inclusion. One patient (patient 9) suffered from an intrahepatic cholangiocarcinoma with refractory malignant ascites.

One patient (patient 7, dose level 3) was not assessable because of a balloon rupture after $5 \mathrm{~min}$ of stop-flow perfu- sion: the pneumatic cuffs were immediately deflated and a second stop-flow perfusion performed 42 min later, but no reliable pharmacokinetic profile could be obtained.

Hypoxia during stop-flow

Hypoxia was considered stringent in patients 5, 6, 8 and 9 . The other perfusions did not fulfil the criteria for hypoxia to be considered as stringent. The evolution of $\mathrm{pH}, p \mathrm{O}_{2}$ and $p \mathrm{CO}_{2}$ during stop-flow are shown on Fig. $2 \mathrm{a}-\mathrm{c}$ (the $\mathrm{pH}, p \mathrm{O}_{2}$ and $p \mathrm{CO}_{2}$ data of patient 1 could not be included in Fig. 2 because of doubts regarding collection times for blood gases testing; however, hypoxia in this patient was assessed as non-stringent). When considering the entire series of experiments, it is to be noticed that hypoxia was more often stringent in the latest patients. This may be the result of improvements in the positioning of the atrial balloons thanks to transoesophageal ultrasonography.

\section{Pharmacokinetic analysis}

\section{Gemcitabine pharmacokinetics}

During the 20 min of stop-flow perfusion, very high levels of gemcitabine were rapidly reached in the abdominalextracorporeal circuit (Fig. 3a). The average $C_{\max }$ values achieved in the circuit were $246,2,039$ and $4,780 \mu \mathrm{g} / \mathrm{ml}$ for the three dose levels $\left(500,750\right.$ and $\left.1,125 \mathrm{mg} / \mathrm{m}^{2}\right)$, respectively (Table 2). Such $C_{\max }$ were 6 to 655 -fold higher than those measured in the peripheral plasma (average ratio 70 , $\mathrm{CV} 423 \%$ ). The $\mathrm{AUC}_{0-20}$ values measured in the stop-flow circuit during perfusion exceeded by a factor of 3-333 those obtained in the peripheral circulation (average ratio
Table 1 Demographics of the nine patients undergoing stopflow perfusion with gemcitabine

\begin{tabular}{lllll}
\hline Characteristics & $\begin{array}{l}\text { All dose } \\
\text { levels }\end{array}$ & $\begin{array}{l}\text { Dose level 1 } \\
500 \mathrm{mg} / \mathrm{m}^{2}\end{array}$ & $\begin{array}{l}\text { Dose level 2 } \\
750 \mathrm{mg} / \mathrm{m}^{2}\end{array}$ & $\begin{array}{l}\text { Dose level 3 } \\
1,125 \mathrm{mg} / \mathrm{m}^{2}\end{array}$ \\
\hline $\begin{array}{l}\text { Total number of patients enrolled } \\
\text { Sex }\end{array}$ & $9^{\mathrm{a}}$ & 3 & 3 & $3^{\mathrm{a}}$ \\
Male & 6 & 2 & 3 & 1 \\
Female & 3 & 1 & 0 & 2 \\
Age (year) & & & 52 & 56 \\
Median & 56 & 65 & $45-56$ & $49-59$ \\
Range & $45-71$ & $59-71$ & & 0 \\
Performance status (ECOG) & & & 0 & 2 \\
0 & 0 & 0 & 2 & 1 \\
1 & 5 & 1 & 1 & 2 \\
2 & 4 & 2 & 3 & 0 \\
Tumour type & 8 & 3 & 2 & 1 \\
Adenocarcinoma of the pancreas & 3 & 1 & 0 & \\
with liver metastases & 1 & 0 & & \\
Cholangiocarcinoma of the liver & & &
\end{tabular}



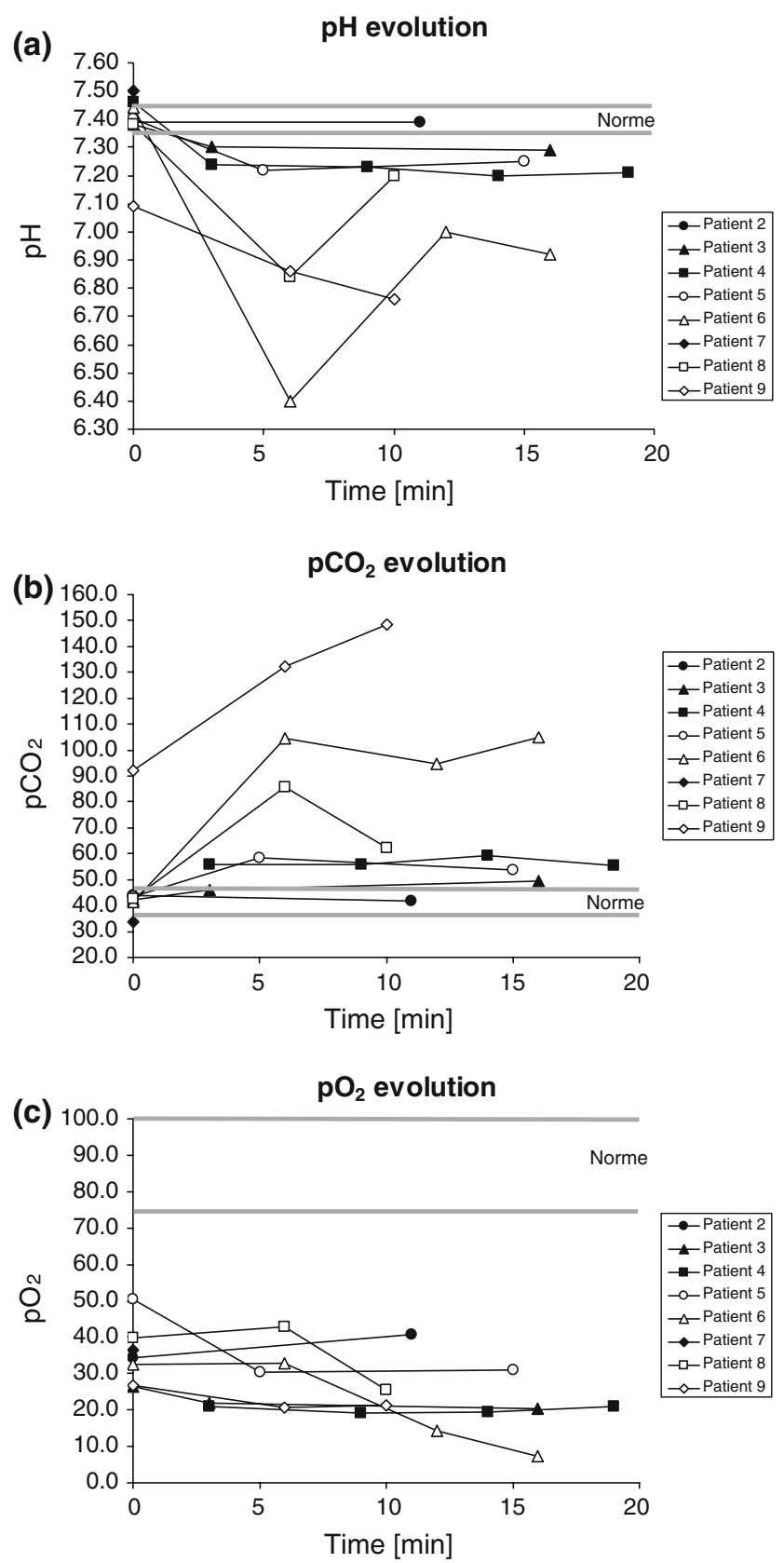

Fig. $2 \mathrm{pH}(\mathbf{a}), p \mathrm{CO} 2$ (b) and $p \mathrm{O} 2$ (c) evolution during stop-flow perfusion. Open symbols: patients with stringent hypoxia conditions; closed symbols: patients with non-stringent hypoxia conditions

32, CV 452\%). Abdominal exposure to gemcitabine was thus much higher than systemic exposure.

However, gemcitabine concentration-time profiles in the peripheral plasma (Fig.3b) indicate that a significant leakage occurred towards the systemic circulation throughout stop-flow perfusion. No burst in peripheral plasma concentration was observed at the end of the perfusion, when the balloons and cuffs were deflated. Interestingly, gemcitabine plasma levels were lower during the first $15 \mathrm{~min}$ of perfusion in the group whose stop-flow procedure was performed under stringent hypoxia (patients 5, 6, 8 and 9), even though they were receiving the upper dose levels (i.e. level 2 for patients 5 and 6 , and level 3 for patients 8 and 9): this may be explained by an improved isolation of the extracorporeal circuit, due to the optimal sonographically assisted atrial positioning of the venous balloon. Further analysis confirmed that the regional exposure to gemcitabine was statistically higher when hypoxia was stringent $\left(P=0.004\right.$ for $C_{\max }$ and $P=0.002$ for $\mathrm{AUC}_{0-20}$, both normalised to gemcitabine dose). The achievement of stringent hypoxia markedly increased the regional to systemic concentration ratio $\left(P=0.02\right.$ for $C_{\max }$ regional/systemic ratio and $P=0.03$ for $\mathrm{AUC}_{0-20}$ regional/systemic ratio): this single factor explains $60 \%$ of the relative variability in both ratio values, as the level of hypoxia is directly related to the degree of vascular occlusion during stop-flow. Fig. 3c presents gemcitabine concentration-time profile in the peripheral plasma during and up to $240 \mathrm{~min}$ after stop-flow perfusion. Gemcitabine exhibits first order elimination rate with a mean terminal half-life $\left(t_{1 / 2 \text { term }}\right)$ of $16 \mathrm{~min}$. The patients treated with the dose level of 500, 750 and $1,125 \mathrm{mg} / \mathrm{m}^{2}$ had systemic $\mathrm{AUC}_{0-\infty}$ values extrapolated to infinity of $6.0,4.8$ and $8.5 \mathrm{mg} \mathrm{h} / \mathrm{l}$, respectively. Systemic $\mathrm{AUC}_{0-\infty}$ values progressed linearly with the dose and varied modestly, which was not the case for regional $\mathrm{AUC}_{0-\infty}$ values (possibly due to confusing effect of improvement in balloon positioning).

\section{$d F d U$ pharmacokinetics}

Quantifiable levels of dFdU, although lower than those of gemcitabine, were found in the abdominal circuit and in the peripheral plasma from the beginning of the stop-flow procedure. This represents gemcitabine rapid metabolism into $\mathrm{dFdU}$ in both compartments (Fig. 3d). The ratio of $\mathrm{AUC}_{0-20}$ of $\mathrm{dFdU}$ over gemcitabine was about ten times higher in peripheral blood, suggesting either a more efficient bioinactivation of gemcitabine in the systemic compartment, or less probably a stronger elimination of $\mathrm{dFdU}$ in the abdominal-extracorporeal circuit. The dFdU concentration-time profile in peripheral plasma during stop-flow perfusion and up to $420 \mathrm{~min}$ after the beginning of the perfusion is shown in Fig. 3e-f. Like gemcitabine, dFdU exhibits a first order elimination rate but has a longer $t_{1 / 2 \text { term }}$ of $248 \mathrm{~min}$. The remaining pharmacokinetic parameters are listed in Table 2.

\section{Tolerability and toxic effects}

The regional chemotherapy treatment by stop-flow perfusion was generally well tolerated. There was no technical or haemodynamic complication during the surgical procedure other than the balloon rupture in patient 7 described above. 
(a)

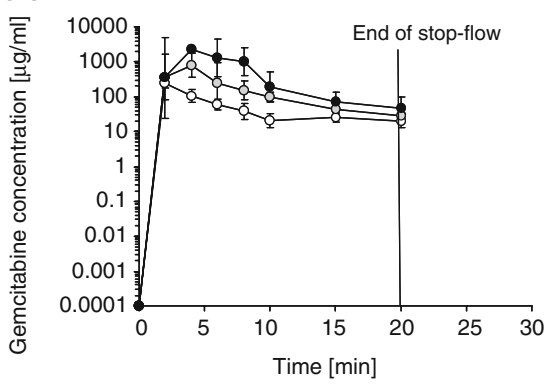

(d)

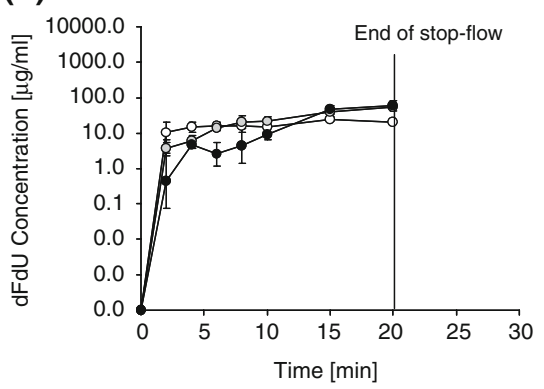

(b)

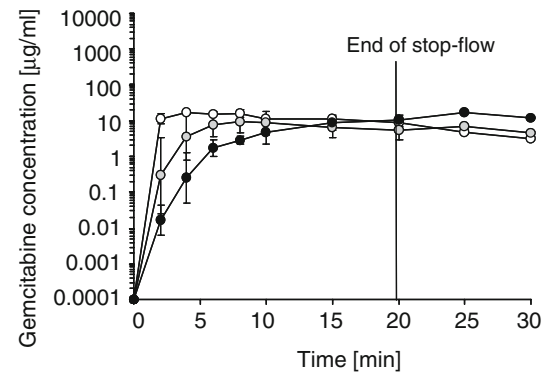

(e)

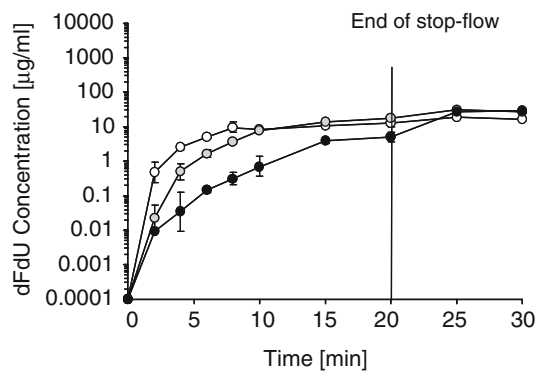

(c)

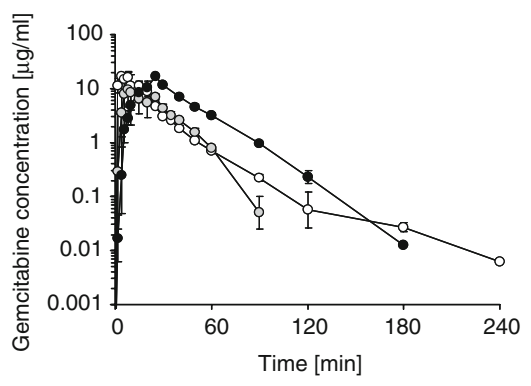

(f)

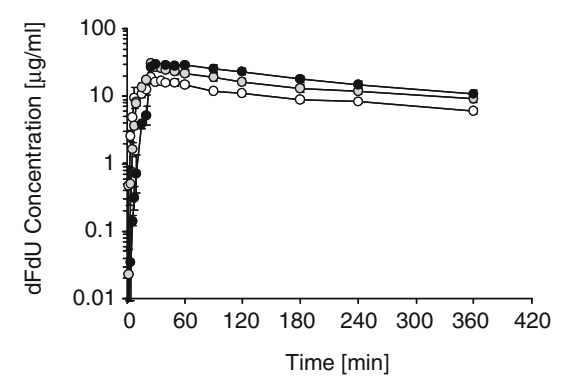

Fig. 3 Mean gemcitabine concentrations ( \pm SEM\%) measured: a in the extracorporeal system during the $20 \mathrm{~min}$ of stop-flow perfusion, $\mathbf{b}$ in the peripheral plasma during $30 \mathrm{~min}$ and $\mathbf{c}$ in the peripheral plasma during 240 min. Mean dFdU concentrations ( \pm SEM\%) measured: $\mathbf{d}$ in

No death occurred during surgery or in the post-operative period. No severe abdominal complication was observed. Patients 2 and 3 recovered spontaneously from grade 1 and patient 6 from grade 2 diarrhoea. Patient 1 suffered from a deep vein thrombosis 3 weeks after the stop-flow perfusion and patient 6 had intermittent paresis of the left limb the day after stop-flow that recovered spontaneously. Laboratory toxicities are reported in Table 3.

There were no grade 4 toxicities. Grade 3 toxicities were mostly hepatic. No renal (creatinine) grade 3 and 4 toxicity was noted. All grade 3 toxicities (haematologic and hepatic) are listed in Table 3.

Concentration-toxicity relationships were also investigated. A positive significant correlation $(r=0.84$ and 0.87 , $P<0.05$ ) was found between the systemic $C_{\max }$ of gemcitabine and the nadir of both leucocyte and neutrophile counts.

\section{Responses and survival}

Eight patients were evaluated for tumour response by abdominal CT 1 month after the stop-flow perfusion. This evaluation was global, in the sense that the patients received only one hypoxic perfusion that was followed by systemic gemcitabine treatments. One patient could not be assessed due to clinical progression of the disease and early death 33 days after the stop-flow perfusion. Four patients had radiological progression of the disease: two of them the extracorporeal system during the $20 \mathrm{~min}$ of stop-flow perfusion, $\mathbf{e}$ in the peripheral plasma during $30 \mathrm{~min}$ and $\mathbf{f}$ in the peripheral plasma during $420 \mathrm{~min}$. open circle: dose level $1\left(500 \mathrm{mg} / \mathrm{m}^{2}\right)$ grey filled circle: dose level $2\left(750 \mathrm{mg} / \mathrm{m}^{2}\right)$; filled circle: dose level $3\left(1,125 \mathrm{mg} / \mathrm{m}^{2}\right)$

developed liver metastases and one bone metastases (patient 6). Two patients had stable disease. Patient 9 (with cholangiocarcinoma of the liver) had a stable abdominalCT picture of the hepatic tumours, but with increased ascites; the disease then progressed rapidly and the patient died 2.5 months after the stop-flow procedure.

The results available for the cancer markers CA 19-9 and CEA, did not indicate any decrease in tumour burden during the first month after stop-flow perfusion.

According to a Kaplan-Meier analysis, the median survival from the time of inclusion was 2.9 months (95\% confidence interval: 1.4-17.7 months).

\section{Discussion}

Stop-flow therapeutic approaches are based on the assumption that neoplasms confined to one anatomical compartment can be exposed to high local concentrations of anticancer agents by using arterial and venous balloon catheters connected to an extracorporeal perfusion circuit without oxygenation. The present study reports the feasability, tolerability and pharmacokinetic profiles of gemcitabine and its main metabolite, $\mathrm{dFdU}$ in nine patients. One patient has been excluded because of a balloon rupture that occurred during the stop-flow procedure. In our little study group, the characteristics of the patients were relatively 


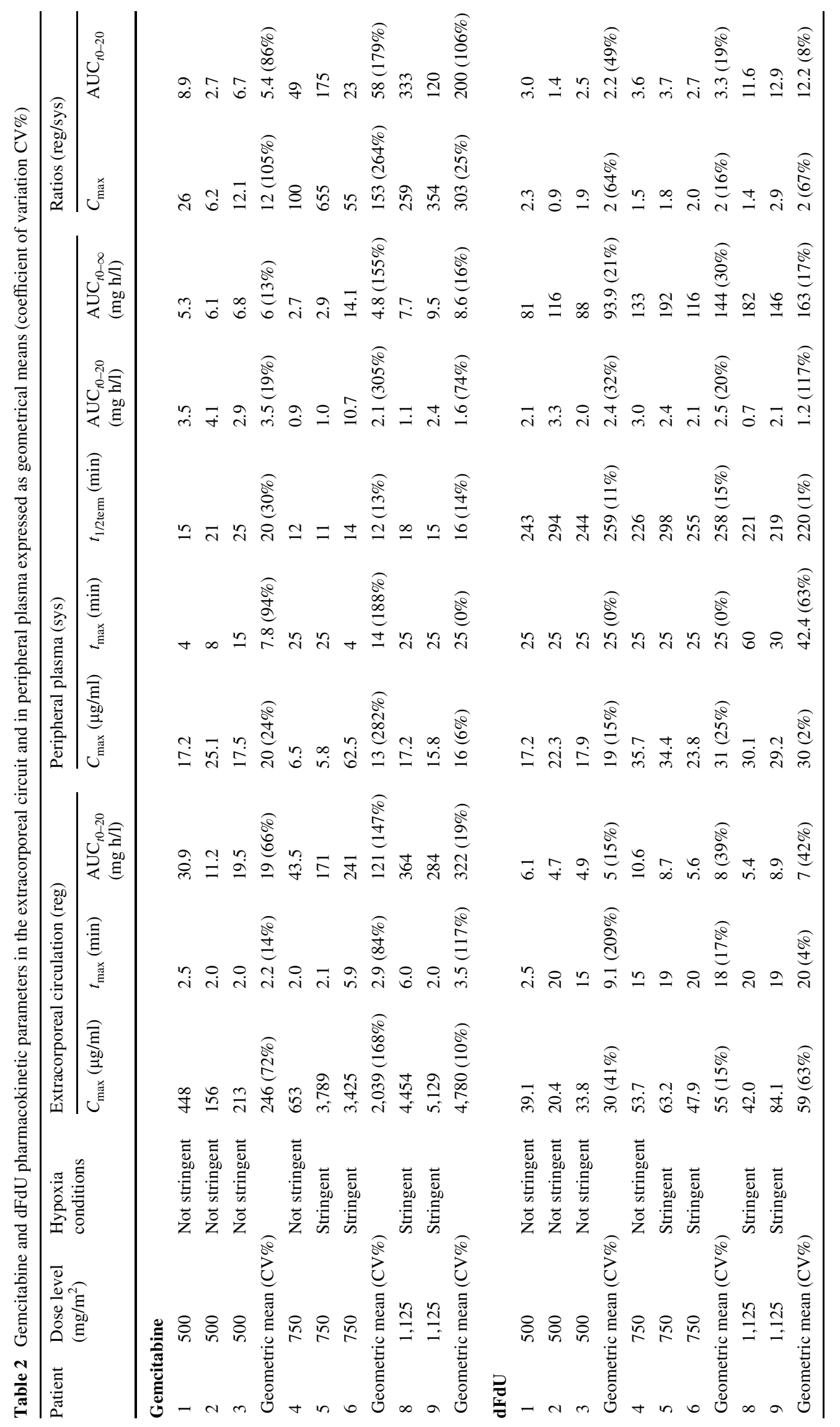


Table 3 Toxicities according to the common terminology criteria for adverse events (CTCAE) [19]

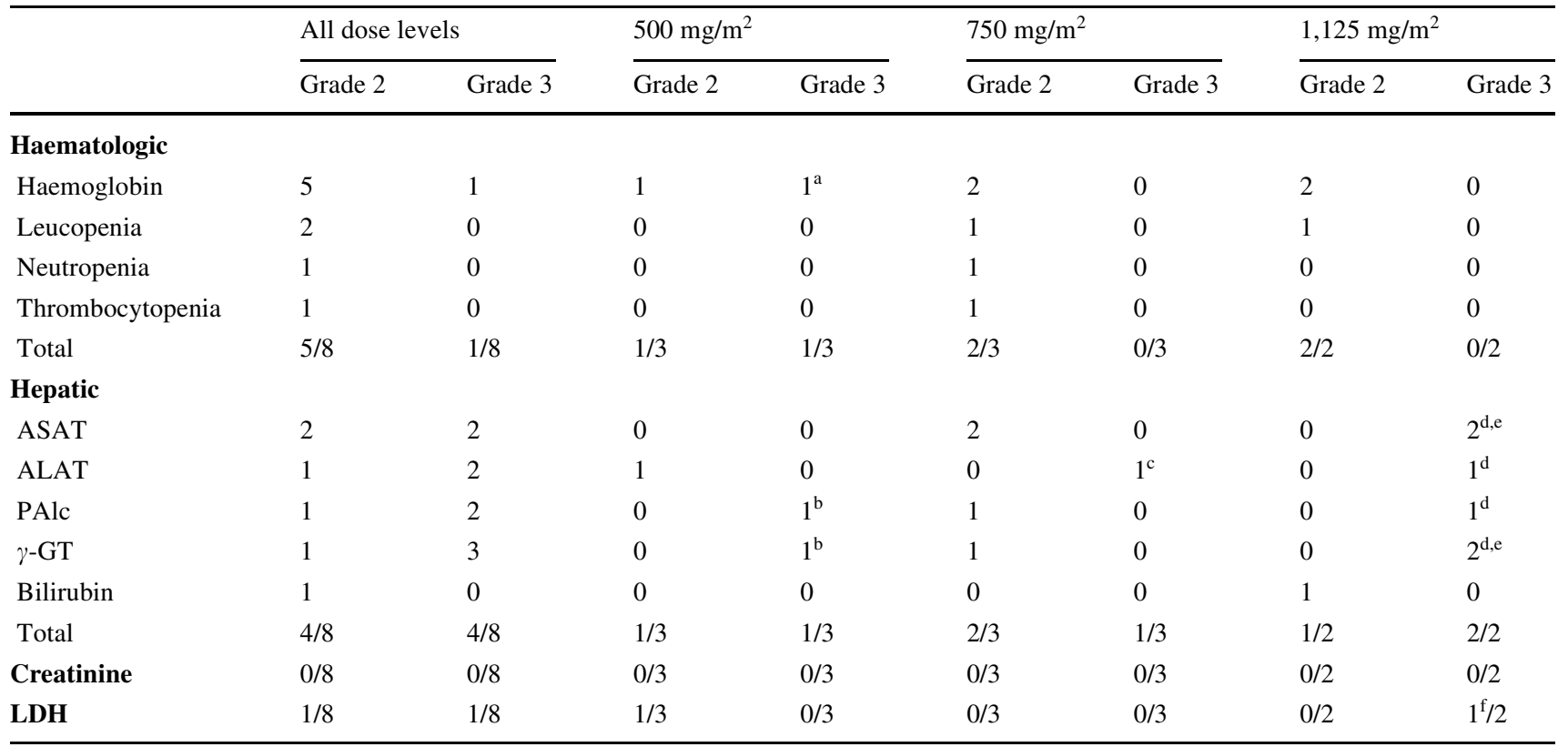

${ }^{a}$ Patient 3 had haemoglobin levels of $73 \mathrm{~g} / 1$ on day 3 after stop-flow

${ }^{\mathrm{b}}$ Patient 1 had a PAlc level of $796 \mathrm{U} / \mathrm{l}$ and a $\gamma$-GT level of 1,096 U/l during the fourth week following stop-flow

${ }^{c}$ Patient 4 had an ALAT level of $317 \mathrm{U} / \mathrm{l}$ on day 4 after stop-flow

${ }^{d}$ Patient 8 had an ASAT level of 207 U/l, an ALAT level of 258 U/l, a PAlc level of 673 U/l and a $\gamma$-GT level of 233 U/l during the third week after stop-flow

${ }^{e}$ Patient 9 had an ASAT level of 293 U/l on day 2 following stop-flow and a $\gamma$-GT level of 503 U/l during the third week following stop-flow

${ }^{\mathrm{f}}$ Patient 9 had a LDH level of 1,238 U/l (5.5 times upper limit of normality) before treatment attributed to the disease. The LDH levels reached a peak of $2,256 \mathrm{U} / \mathrm{l}$, i.e. 1.8 times higher than baseline

heterogeneous: eight patients had advanced adenocarcinoma of the pancreas, with three of them having liver metastases, and one suffering from an intrahepatic cholangiocarcinoma with refractory malignant ascites.

The pharmacokinetic assessments performed proved that the exposure to gemcitabine was indeed markedly higher in the regional circuit than in the peripheral plasma. The exposure was, however, significantly greater for patients perfused under stringent vascular isolation conditions, inducing deep hypoxia. In our study, the regional over systemic ratios of $\mathrm{AUC}_{0-20}$ measured under non-stringent hypoxic conditions (range 2.7-49) were significantly lower than those measured under stricter hypoxic conditions. The latter values were much higher (range 23-333) than those reported in literature for comparable abdominal or pelvic stop-flow perfusions [7, 10, 16-18]. Meyer et al. for example, reported an AUC ratio of 4 [10] and Petrowski et al. of 6.5 after abdominal stop-flow of mitomycin C [7]. In the limited number of studies available, various drugs such as mitomycin $\mathrm{C}$ and doxorubicin were administered by stopflow perfusion, which makes comparisons with gemcitabine difficult. However, our study highlights that hypoxic conditions are related to the degree of vascular isolation of the regional circuit. This deserves, therefore, very close monitoring which is best achieved by transoesophageal ultrasonography: to the best of our knowledge earlier studies did not use this technique.

In the present study, the $C_{\max }$ levels of gemcitabine measured in the circuit were very high (up to $5,129 \mu \mathrm{g} / \mathrm{ml}$ ). By comparison, systemic i.v. administration of similar doses has been reported to yield peak plasma concentrations of $30-40 \mu \mathrm{g} / \mathrm{ml}$ [19-27]. As the intracellular phosphorylation of gemcitabine is known to be saturable [19], the benefit of very high gemcitabine levels remains questionable. Others have indeed shown that gemcitabine peak levels of 4-5 $\mu \mathrm{g} /$ $\mathrm{ml}$ enable a maximal production rate of the pharmacologically active gemcitabine triphosphate that accumulates in mononuclear cells [19]. Higher levels may then saturate the rate of cellular accumulation in a majority of patients. It is, however, not known whether gemcitabine disposition in mononuclear cells is similar to that in tumour cells. In addition, efficient penetration into solid tumours may require higher gemcitabine plasma levels. The transport and cellular metabolism of gemcitabine in cancer tissues and solid tumour masses deserve therefore further research. The average systemic $C_{\max }, t_{1 / 2 \text { term }}$ and $\mathrm{AUC}_{0-\infty}$ levels of gemcitabine and $\mathrm{dFdU}$, according to the delivered dose, compare well with the pharmacokinetic data reported in the 
literature [19-27]. This indicates that a $20 \mathrm{~min}$ stop-flow procedure does not significantly modify the overall systemic exposure to gemcitabine and its metabolite.

The toxicities encountered were acceptable considering the complexity of the procedure. We did not observe increased toxicities in the four stringent perfused patients. However, as this sub-group is very small, the tolerability of the procedure should be interpreted with some caution. Overall the toxicities were mostly hepatic, but it remains difficult to differentiate between the respective contributions of systemic and regional exposures. Liver toxicities may be favoured by the stop-flow procedure itself, by hypoxia and/or by the very high regional gemcitabine concentrations. Studies in liver transplantation may give a clue as they indicated that the liver is highly sensitive to the reperfusion injury mediated by reactive oxygen species [28]. In addition, gemcitabine itself is known to cause transient elevations of liver function tests after i.v. administration in two-thirds of patients and may therefore have contributed to the observed toxicities [29]. Interestingly, we did not observe any gall bladder toxicity, contrary to other authors who perform stop-flow with mitomycin $\mathrm{C}$ for liver metastases: in their study, hypoxia was essentially toxic for the gallbladder, with ischemic cholecystitis occurring in $3 / 15$ cases (14\%) [30]. Finally, it seems that the drugs used for general anaesthesia, including halogenated agents may also play a significant role in the observed hepatotoxicity. In brief, several reasons, taken separately or together, may be incriminated for the liver function tests elevations but we feel that hypoxia was the major cause.

Even though the clinical response was not a primary endpoint in this phase I study, the absence of any objective therapeutic response is disappointing. This may actually have been expected because gemcitabine, although the standard of care in advanced adenocarcinoma of the pancreas, is prescribed on the basis of an improved quality of life, with a very short actual survival increase compared to 5-FU (5.6 vs. 4.4 months) [31]. Such survival data are therefore in line with our median survival of 2.9 months (95\% confidence interval $1.4-17.7$ months). This result highlights the current lack of efficacious treatment for a malignancy with a disastrous prognostic.

In conclusion, gemcitabine may not have been the best choice in the setting of terminal pancreatic cancer, due to its questionable activity under hypoxic conditions. As cellular bio-activation into gemcitabine-triphosphate is an energy-dependent process, it may decrease under hypoxia. This, in turn, may slow down DNA synthesis and protect tumour cells against drug action. However, our study demonstrates that the stop-flow procedure was safely performed on these nine patients with various advanced abdominal malignancies. The toxicity was evaluated as acceptable until a dose level of $1,125 \mathrm{mg} / \mathrm{m}^{2}$ and the regional exposure to an anticancer agent could be enhanced dramatically using an optimised perfusion technique. In the future, it should be possible to treat patients with this approach using bioreductive drugs such as mitomycin $\mathrm{C}$, melphalan, or tirapazamine - a more recently developed agent currently under clinical development [32]. Another promising strategy may consist in delivering hypoxia-selective gene therapy or targeted therapy directed against the hypoxia inducible factor 1 (HIF-1), expressed at high levels in most cancer cells [33]. Before assessing whether these new drugs improve the response to chemotherapy, another phase I trial with escalating doses would be warranted in order to study their toxicity.

Acknowledgments This study was supported in part by an unrestricted grant from Eli Lilly Switzerland. A. K. has received a grant from the "Fondation pour la Recherche en Pharmacologie clinique", Lausanne, Switzerland.

\section{References}

1. Michaud DS (2004) Epidemiology of pancreatic cancer. Minerva Chir 59(2):99-111

2. Jemal A, Murray T, Samuels A, Ghafoor A, Ward E, Thun MJ (2003) Cancer statistics, 2003. CA Cancer J Clin 53:5-26

3. Aigner K (1993) Aortic stop-flow infusion (ASI) and hypoxic abdominal perfusion (HAP) for disseminated bulk peritoneal carcinomatosis: rationale and technique. Reg Cancer Treat 6:3

4. Lorenz M, Heinrich S, Staib-Sebler E, Köhne CH, Wils J, Nordlinger B, Encke A (2000) Regional chemotherapy in the treatment of advanced pancreatic cancer-is it relevant? Eur J Cancer 36:957-965

5. Pilati P, Mocellin S, Miotto D, Rossi CR, Codello L, Foletto M, Scalerta R, Vieceli G, Ceccherini M, Nitti D, Lise M (2002) Stop-flow technique for loco-regional delivery of antiblastic agents: literature review and personal experience. Eur J Surg Oncol 28:544-553

6. Fiorentini G, Poddie D, Ricci S (1996) Intra-aortic stop-flow infusion (IASFI) with hypoxic abdominal perfusion (HAP) in UICC stage III/IV pancreatic carcinoma (PC): report of a phase II study. Reg Cancer Treat 9:88-91

7. Petrowski H, Heinrich S, Staib-Sebler E, Gog C, Jandhon G, Lorenz M (1998) Isolated hypoxic perfusion with mitomycin C confers no benefit for patients with advanced pancreatic cancer. Langenbecks Arch Chir 115(suppl 2):1351-1353

8. Gebauer T, Ridwelski K, Fahlke J, Lippert H (1998) Locoregional and systemic therapy in advanced pancreatic carcinoma. Langenbecks Arch Chir 115(suppl 2):1344-1347

9. Van Ijken MGA, Van Etten B, Guetens G, Ten Hagen TLM, Jeekel J, De Bruijn EA, Eggermont AMM, Van Eijck CHJ (2004) Balloon catheter hypoxic abdominal perfusion with mitomycin $\mathrm{C}$ and melphalan for locally advanced pancreatic cancer: a phase III trial. Eur J Surg Oncol 30:671-680

10. Meyer F, Ridwelski K, Bebauer T, Grote R, Martens-Lobenhoffer J, Lippert $H$ (2005) Pharmacokinetics of the antineoplastic drug mitomycin $\mathrm{C}$ in regional chemotherapy using the aortic stop-flow technique in advanced pancreatic carcinoma. Chemotherapy $51: 1-8$

11. Common Terminology Criteria for Adverse Events v3.0 (CTCAE) (2003) http://ctep.cancer.gov

12. Chapuzet E, Mercier N, Bervoas-Martin S, Boulanger B, Chevalier P, Chiap P, Grandjean D, Hubert P, Lagorce P, Lallier M, Laparra MC, Laurentie M, Nivet JC (1997) Méthodes 
chromatographiques de dosage dans les milieux biologiques: stratégie de validation: rapport d'une commission SFSTP. STP Pharma Prat 7:169-194

13. Boulanger B, Chapuzet E, Chiap P, Cohen N, Compagnon PA, Dewe W, Feinberg M, Lallier M, Laurentie M, Mercier N, Muzard G, Nivet C, Valat L (2003) Validation of quantitative analytical procedure, harmonization of approaches. STP Pharma Prat 13:101-138

14. Shah VP, Midha KK, Dighe S, Mc Gilveray IJ, Skelly JP, Yacobi A, Layloff T, Viswanathan CT, Cook CE, Mc Dowall RD, Pittman KA, Spector S (1991) Analytical methods validation: bioavailability, bioequivalence and pharmacokinetic studies. Eur J Drug Metab Pharmacokinet 4:249-255

15. Shah VP, Midha KK, Findlay JW, Hill HM, Hulse JD, McGilveray IJ, McKay G, Miller KJ, Patnaik RN, Powell ML, Tonelli A, Viswanathan CT, Yacobi A (2000) Bioanalytical method validation-a revisit with a decade of progress. Pharm Res 17:15511557

16. Strocchi E, Laffaioli RV, Facchini G, Mantovani G, Ricci S, Cavallo G, Tortoriello A, D'Angelo R, Formato R, Rosato G, Fiore F, Laccarino V, Petrella G, Memoli B, Santangelo M, Camaggi CM (2004) Stop-flow technique for loco-regional delivery of high dose chemotherapy in the treatment of advanced pelvic cancer. Eur $\mathbf{J}$ Surg Oncol 30:663-670

17. Guadagni S, Fiorentini G, Palumbo G, Valenti M, Russo F, Cantore M, Deraco M, Vaglini M, Amicucci G (2001) Hypoxic pelvic perfusion with mitomycin $\mathrm{C}$ using a simplified balloon-occlusion technique in the treatment of patients with unresectable locally recurrent rectal cancer. Arch Surg 136:105-112

18. Guadagni S, Aigner KR, Palumbo G, Cantore M, Fiorentini G, Pozone T, Deraco M, Clerico M, Chaudhuri PK (1998) Pharmacokinetics of mitomycin $\mathrm{C}$ in pelvic stopflow infusion and hypoxic pelvic perfusion with and without hemofiltration: a pilot study of patients with recurrent unresectable rectal cancer. J Clin Pharmacol 38:936-944

19. Grunewald R, Abbruzzese JL, Tarassoff P, Plunket W (1991) Saturation of $2^{\prime}, 2^{\prime}$-difluorodeoxycytidine $5^{\prime}$-triphosphate accumulation by mononuclear cells during a phase I trial of gemcitabine. Cancer Chemother Pharmacol 27:258-262

20. Abbruzzese JL, Grunewald R, Weeks EA, Gravel D, Adams T, Nowak B, Mineishi S, Tarassoff P, Satterlee W, Raber MN, Plunkett W (1991) A phase I clinical, plasma, and cellular pharmacology study of gemcitabine. J Clin Oncol 9:491-498

21. Allerheiligen S, Johnson R, Hatcher B, Freeman K, Tarassoff P, Voi M, Dorr A (1994) Gemcitabine pharmacokinetics are influenced by gender, body surface area, and duration of infusion. Proc Am Soc Clin Oncol 13:136
22. Johnson SA (2000) Clinical pharmacokinetics of nucleoside analogues: focus on haematological malignancies. Clin Pharmacokinet 39:5-26

23. Patnaik A, Eckhardt SG, Izbicka E, Tolcher AA, Hammond LA, Takimoto CH, Schwartz G, McCreery H, Goetz A, Mori M, Terada K, Gentner L, Rybak ME, Richards H, Zhang S, Rowinski EK (2003) A phase I, pharmacokinetic, and biological study of the farnesyltransferase inhibitor tipifarnib in combination with gemcitabine in patients with advanced malignancies. Clin Cancer Res 9:4761-4771

24. Kroep J, Giaccone G, Voorn DA, Smit EF, Beijnen JH, Rosing H, Van Moorsel CJA, Van Groeningen CJ, Postmus PE, Pinedo HM, Peters GJ (1999) Gemcitabine and paclitaxel: pharmacokinetic and pharmacodynamic interactions in patients with non-small-cell lung cancer. J Clin Oncol 17:2190-2197

25. Van Moorsel CJA, Kroep JR, Pinedo HM, Veerman G, Voorn DA, Postmus PE, Vermorken JB, Van Groeningen CJ, Van der Vijgh WJF, Peters GJ (1999) Pharmacokinetic schedule finding study of the combination of gemcitabine and cisplatin with solid tumors. Ann Oncol 10:441-448

26. Fogli S, Danesi R, De Braud F, De Pas T, Curigliano G, Giovannetti E, Del Tacca M (2001) Drug distribution and pharmacodynamic relationship of paclitaxel and gemcitabine in patients with non-small-cell lung cancer. Ann Oncol 12:1553-1559

27. Fogli S, Danesi R, Gennari A, Donati S, Conte PF, Del Tacca M (2002) Gemcitabine, epirubicin and paclitaxel: pharmacokinetic and pharmacodynamic interactions in advanced breast cancer. Ann Oncol 13:919-927

28. Kupiec-Weglinski JW, Busuttil RW (2005) Ischemia and reperfusion injury in liver transplantation. Transplant Proc 37(4):1653-1656

29. Green MR (1996) Gemcitabine safety overview. Semin Oncol 23:32-35

30. Roversi R, Cavallo G, Ricci S, Rossi G, Roversi M, Fiorentini G (1997) Antiblastic hypoxic stop-flow perfusion in the treatment of liver metastasis: preliminary results. Radiol Med (Torino) 93(4):410-417

31. Burris HA III, Moore MJ, Andersen JS, Green MR, Rothenberg ML, Modiano MR, Cripps MC, Portenoy RK, Storniolo AM, Tarassoff P, Nelson R, Dorr FA, Stephens CD, Von Hoff DD (1997) Improvement in survival and clinical benefit with gemcitabine as first-line therapy for patients with advanced pancreas cancer: a randomized trial. J Clin Oncol 15:2403-2413

32. Zaffaroni N, Fiorentini G, De Giorgi U (2001) Hyperthermia and hypoxia: new developments in anticancer chemotherapy. Eur J Surg Oncol 27:340-342

33. Brown JM, Wilson WR (2004) Exploiting tumour hypoxia in cancer treatment. Nat Rev Cancer 4:437-447 